\title{
ESTUDO DE CASO SOBRE A QUALIDADE DA ÁGUA DO RIO POTENGI NA CIDADE DE SÃO PAULO DO POTENGI, RIO GRANDE DO NORTE, BRASIL
}

\author{
D. M. TORRES*, M. D. B. GOMES, E. K. F. ANDRADE, R. D. R. SILVA \\ Instituto Federal de Educação, Ciência e Tecnologia do Rio Grande de Norte \\ dayana.torres@ifrn.edu.br*
}

Artigo submetido em 25/11/2019 e aceito em 11/12/2019

DOI: $10.15628 /$ holos.2019.9193

\begin{abstract}
RESUMO
A água é um recurso imprescindível para a manutenção da vida. Com isso, a utilização sem precedentes e a poluição dos corpos hídricos, oriunda do lançamento de efluentes de forma inadequada, têm sido alvo de discussões, com a finalidade de avaliar os impactos ambientais e a qualidade da água nos dias atuais. Como as atividades humanas são geradoras de resíduos potencialmente poluidores ao meio ambiente, a gestão inadequada desses resíduos pode potencializar os impactos ambientais. Tendo isso em vista, este estudo investigou a qualidade da água do Rio Potengi, a partir dos padrões estabelecidos nas resoluções do Conselho Nacional de Meio Ambiente (CONAMA) n 357/05 e
\end{abstract}

274/00. Para tanto, foram realizadas 75 coletas em 5 trechos do rio em análise, na cidade de São Paulo do Potengi, localizada no Rio Grande do Norte, estado do nordeste brasileiro. A qualidade das águas foi avaliada através de parâmetros, acatando os requisitos para análises físico-químicas e microbiológicas, estipulados em APHA et al. (2017). Os resultados das coletas apontam altos índices de coliformes termotolerantes e baixa concentração de oxigênio dissolvido, estando isso relacionado com o lançamento inadequado de efluentes domésticos no rio. O estudo mostra-se relevante por inteirar a comunidade sobre o nível de poluição dos trechos do rio, que são utilizados para balneabilidade.

PALAVRAS-CHAVE: Rio Potengi, qualidade das águas, balneabilidade.

\section{CASE STUDY ON POTENGI RIVER WATER QUALITY IN THE CITY OF SÃO PAULO DO POTENGI, RIO GRANDE DO NORTE, BRAZIL}

\begin{abstract}
Water is an indispensable resource for maintaining life. As a result, unprecedented use and pollution of water bodies from improperly discharged effluents have been the subject of discussions to assess environmental impacts and water quality today. As human activities generate potentially polluting waste to the environment, improper management of this waste can increase environmental impacts. In view of this, this study investigated the water quality of the Potengi River, based on the standards established in the National Environment Council (CONAMA) resolutions No. $357 / 05$ and $274 / 00$. To this end, 75 collections were
\end{abstract}

performed in 5 sections of the river under analysis, in the city of São Paulo do Potengi, located in Rio Grande do Norte, northeastern Brazilian state. Water quality was evaluated through parameters, complying with the requirements for physicochemical and microbiological analysis, stipulated in APHA et al. (2017). The collection results indicate high rates of thermotolerant coliforms and low concentration of dissolved oxygen, which is related to the inadequate discharge of domestic effluents into the river. The study is relevant for informing the community about the pollution level of the river stretches that are used for bathing.

KEYWORDS: Potengi River, water quality, bathing. 


\section{INTRODUÇÃO}

O Rio Potengi é um dos principais mananciais do Rio Grande do Norte, estado localizado no Nordeste do Brasil. Banhando 9 municípios do estado ele e é de extrema importância para a movimentação de atividades econômicas como pesca, carcinicultura, agricultura e dessedentação animal, bem como dispõe de grande relevância histórica, cultural e social para o povo potiguar.

Diversos trechos do Rio Potengi se encontram em estado de vulnerabilidade, em decorrência da falta de cuidados da população usuária e de atenção por parte dos gestores públicos. Sua poluição é perceptível, em virtude de algumas características organolépticas desagradáveis, o que incitou a presente pesquisa.

Com o passar dos anos, o rio sofreu alterações em suas características naturais. O crescimento desordenado das cidades, a falta de estrutura e a falta de saneamento básico são os principais causadores. Este último, sobretudo, continua sendo um agravante da degradação ambiental e de problemas socioambientais e de saúde pública.

Considerando o atual problema em relação à poluição identificada no Rio Potengi, esta pesquisa visa contribuir como subsídio para gestão e tomada de decisão, por parte do poder público, no tocante à qualidade e à balneabilidade das águas do Rio Potengi. Nesse sentido, temse como objetivo investigar a qualidade da água do Rio Potengi a partir de padrões estabelecidos nas Resoluções do Conselho Nacional de Meio Ambiente (CONAMA) no 357/2005 e no 274/2000.

\section{REVISÃO BIBLIOGRÁFICA}

A utilização incorreta e não sustentável, que conduz à deterioração dos recursos hídricos, ocasiona diversos impactos. Destaca-se a contaminação de populações dependentes da pesca e a modificação da qualidade e da quantidade da água dos ecossistemas naturais e artificiais, o que provoca alterações dos padrões de vazão devido a assoreamento; modificação da geomorfologia fluvial e destruição de áreas de recarga de aquíferos e de hábitats marginais (SILVA et al., 2011).

No Brasil e no RN, a falta de tratamento de esgotos é uma questão particularmente grave, com índices de esgoto tratado que não superam 41\% (FIGUEIREDO E FERREIRA, 2017). De acordo com o Plano Municipal de Saneamento de São Paulo do Potengi (2011) a zona urbana da referida 
cidade possui um sistema de esgotamento sanitário dividido em 03 bacias, que são gerenciadas pela CAERN (Companhia de Águas e Esgotos do Rio Grande do Norte).

Segundo o Sistema Nacional de Informações sobre Saneamento Básico (SNIS), em 2008, a porcentagem de atendimento do sistema de esgotamento da CAERN no município era de 13,7\%. Muitos bairros, portanto, não recebem o tratamento adequado de seus efluentes como, por exemplo, o bairro Assunção, que apesar de ser detentor de rede coletora de esgotos executada pela prefeitura, tem seus esgotos lançados in natura no Rio Potengi.

Esses significativos aportes de matéria orgânica, nutrientes e demais poluentes têm sido relatados como principais responsáveis pela eutrofização de mananciais superficiais e têm gerado preocupação crescente com o alto grau de poluição em que se encontram, hoje, os rios e ambientes de água doce (COSTA et al., 2016).

A eutrofização pode levar à alteração no sabor, no odor, na turbidez e na cor da água, bem como redução do oxigênio dissolvido (OD). Tais condições provocam crescimento excessivo de plantas aquáticas, mortandade de peixes e outras espécies aquáticas, além do comprometimento das condições mínimas para o lazer na água (SMITH E SCHINDLER, 2009).

Além dos prejuízos para o ecossistema aquático, o despejo irregular de efluentes, sejam eles domésticos ou industriais, ainda é uma das principais causas de diversas doenças de veiculação hídrica. A poluição das águas é, de longe, o problema ambiental mais sério do Brasil, onde $80 \%$ de todas as doenças de origem hídrica e um terço dos óbitos estão relacionados à contaminação da água (BRASIL, 2013).

Inúmeras epidemias e doenças que acometem o trato gastrointestinal apresentam como fonte de infecção a água poluída, tendo em vista que o esgoto contém diferentes microrganismos como bactérias do grupo coliforme, vírus e vermes que podem causar doenças ou indicar a presença de patógenos. Doenças vinculadas a essa água são causadas por patógenos de etiologia entérica, ou seja, provenientes do intestino de humanos ou de animais, transmitidos por via fecal-oral (MELLO E OLIVO, 2016).

O Brasil é, na sua generalidade, um país com elevada incidência de doenças intestinais transmitidas pela água. Esses índices se refletem nas elevadas taxas de mortalidade, em especial nas de mortalidade infantil, que vêm sendo constatadas ao longo dos anos. Tais índices de mortalidade estão relacionados ao desenvolvimento industrial, crescimento demográfico e ocupação do solo de forma intensa e acelerada, o que compromete os recursos hídricos 
destinados ao consumo humano, recreação e múltiplas atividades, e aumenta, potencialmente, o risco de transmissão de doenças de origem hídrica (BRASIL, 2013).

\section{METODOLOGIA}

Esta pesquisa é de abordagem quantitativa e seus dados foram coletados através de 7 campanhas de monitoramento para avaliar a qualidade da água em um trecho urbano do Rio Potengi, na cidade de São Paulo do Potengi-RN. Os critérios utilizados para a escolha dos locais de coleta estão relacionados à proximidade do trecho com residências e com locais que eram ou são utilizados pela comunidade para recreação, pesca e criação de animais. Foram definidos 5 locais para realização do monitoramento, os quais são apresentados na Figura 1.

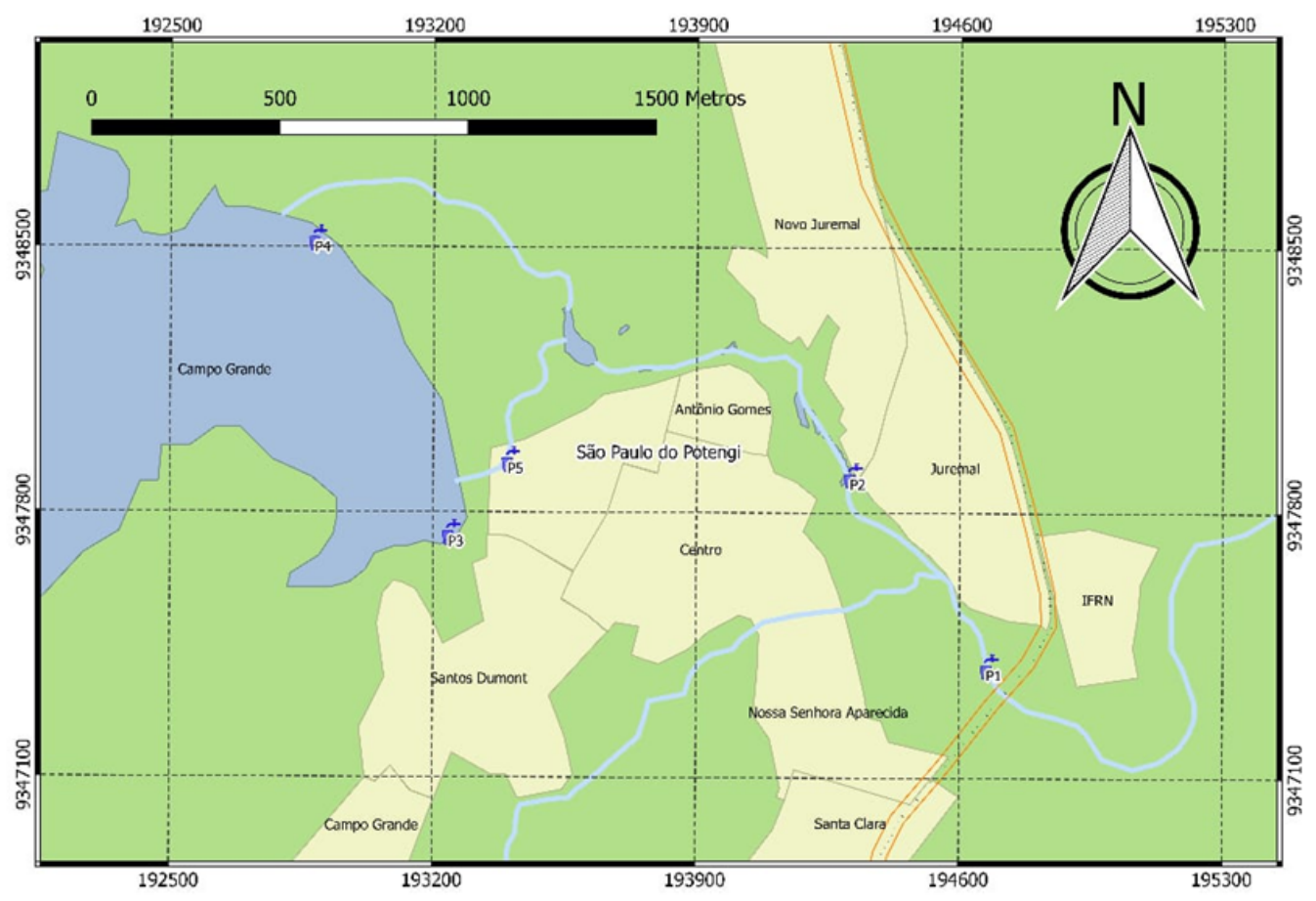

Figura 1: Mapa de localização dos pontos de monitoramento.

Os pontos escolhidos apresentam as seguintes características:

- P1: situado na RN 120, é perceptível, em sua localidade, a presença da mata ciliar, e a criação de alguns animais (Figura 2a);

- P2: nomeado de passagem molhada, é situado em meio a alguns comércios e residências, onde também existem criação de animais (Figura 2b);

- P3: situado no reservatório Campo Grande, tem grande proximidade com as residências (Figura 2c); 
- P4: também situado no reservatório Campo Grande, é um pouco afastado das residências, porém próximo a algumas plantações de hortaliças (Figura 2d); e por último,

- P5: situado na comporta - lugar antes comumente usado para recreação, mas que se encontra aparentemente desativado -, apresenta ocupação urbana e criação de animais nas adjacências (Figura 2e).
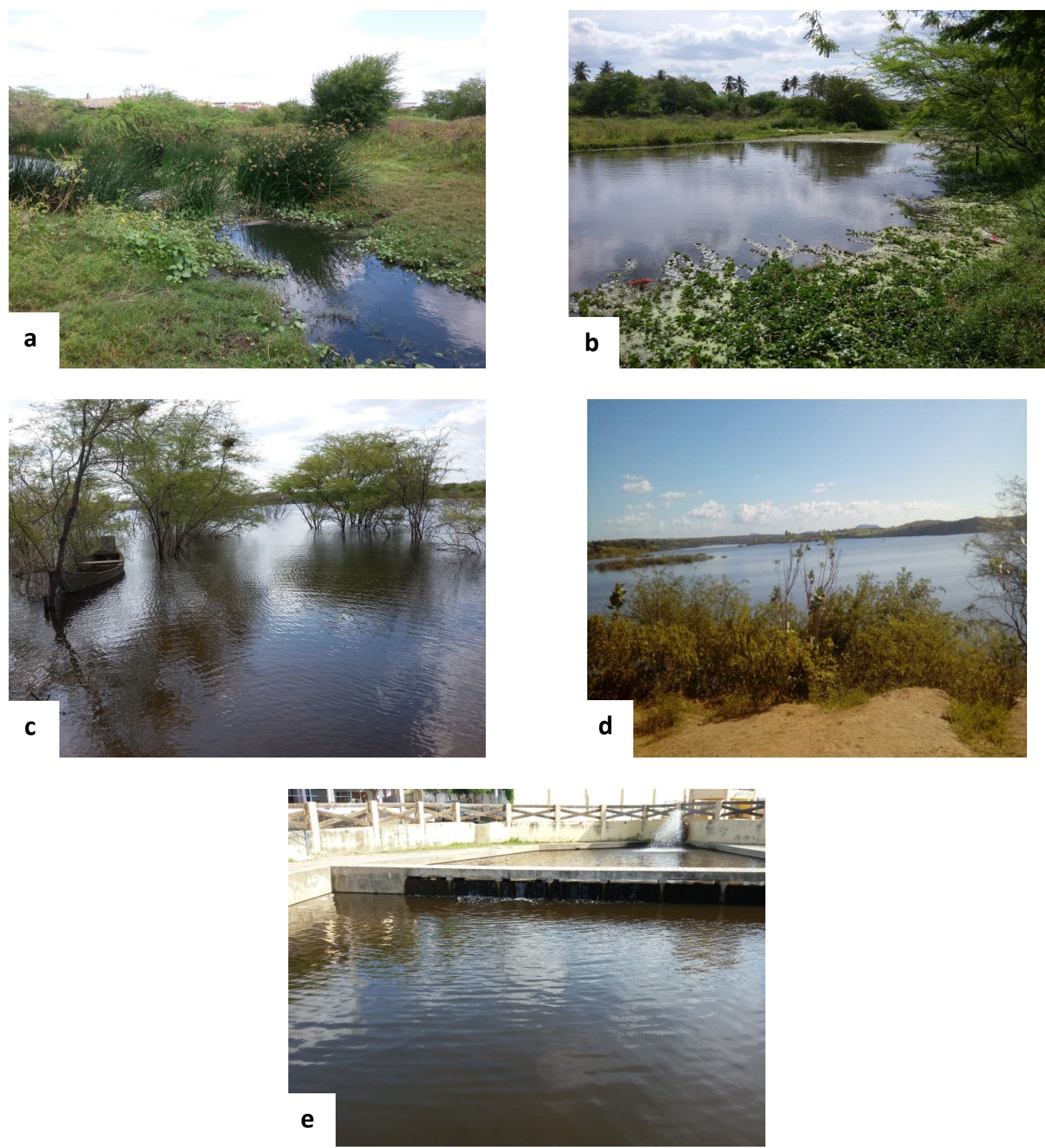

Figura 2: Pontos monitorados

Fonte: Acervo dos autores 
As coletas ocorreram entre os meses de abril e de setembro de 2018 , com frequência mensal.

Os indicadores físico-químicos e microbiológicos analisados e os respectivos métodos analíticos estão apresentados na Tabela 1. As análises foram realizadas no Laboratório de Análises de Águas, Efluentes e Solos do Instituto Federal de Educação, Ciência e Tecnologia do Rio Grande do Norte (IFRN), Campus São Paulo do Potengi.

Para as análises físico-químicas, foram coletados aproximadamente 2 litros de amostra e, para as análises microbiológicas, cerca de 100 mililitros. Tais amostras foram armazenadas em recipientes previamente esterilizados e, após a coleta, foram acondicionadas em caixa térmica, a uma temperatura média de 4 oㅡ, para preservar seus constituintes físico-químicos e microbiológicos.

Tabela 1: Indicadores físico-químicos e microbiológicos analisados e respectivas metodologias.

\begin{tabular}{|c|c|c|c|}
\hline Variáveis & Unidade & Método & Referência \\
\hline Temperatura & $\stackrel{\circ}{C}$ & $\begin{array}{c}\text { Termômetro com filamento de } \\
\text { mercúrio }\end{array}$ & \multirow{10}{*}{$\begin{array}{c}\text { APHA, AWWA e WEF } \\
\text { (2017) }\end{array}$} \\
\hline $\mathrm{pH}$ & - & Potenciométrico & \\
\hline Sólidos totais & $\mathrm{mg} / \mathrm{L}$ & $\begin{array}{c}\text { Gravimétrico - Filtração a vácuo e } \\
\text { secagem a } 103 \text { ㄷ }-105 \text { c }\end{array}$ & \\
\hline $\begin{array}{l}\text { Oxigênio } \\
\text { dissolvido }\end{array}$ & $\mathrm{mg} / \mathrm{L}$ & Potenciométrico & \\
\hline Turbidez & UNT & Nefelométrico & \\
\hline Cor aparente & $\mathrm{uH}$ & Colorimétrico & \\
\hline $\begin{array}{l}\text { Alcalinidade } \\
\text { total }\end{array}$ & $\mathrm{mgCaCO}_{3} / \mathrm{L}$ & Titulométrico com $\mathrm{H}_{2} \mathrm{SO}_{4} 0,02 \mathrm{~N}$ & \\
\hline Dureza Total & $\mathrm{mg} / \mathrm{L}$ & Titulométrico com EDTA & \\
\hline Dureza de Cálcio & $\mathrm{mg} / \mathrm{L}$ & Titulométrico com EDTA & \\
\hline $\begin{array}{l}\text { Coliformes } \\
\text { termotolerantes }\end{array}$ & $\mathrm{NMP} / 100 \mathrm{~mL}$ & Tubos múltiplos & \\
\hline
\end{tabular}

Os dados foram organizados e sintetizados através de planilhas eletrônicas para realização de estatística descritiva e elaboração de gráficos de barras e box plot, para melhor apresentação e análise dos resultados.

\section{RESULTADOS E DISCUSSÃO}

Os resultados obtidos estão apresentados na Tabela 1, na qual os padrões e parâmetros foram analisados de acordo com as Resoluções CONAMA no 357/2005 e no 274/2000. Devido à ausência de alguns parâmetros nas resoluções do CONAMA, também foram utilizados, como 
subsídio para a pesquisa, a Portaria de Consolidação no 5/2017 do Ministério da Saúde e os valores adotados nos estudos de Von Sperling (2014).

Quando comparados com as resoluções vigentes no Brasil, alguns parâmetros analisados nos pontos monitorados estão em conformidade com o recomendado, como os valores de $\mathrm{pH}$, nitrato, turbidez e temperatura, que não apresentam uma variação significativa e permanecem dentro da faixa de valor recomendado. Entretanto, outros parâmetros encontram-se acima dos valores estabelecidos nas resoluções estudadas.

Tabela 2: Qualidade das águas do Rio Potengi (valores médios, mínimo e máximo).

\begin{tabular}{|c|c|c|c|c|c|c|c|c|c|c|c|}
\hline 옹 & ० & $\frac{O}{\mathscr{0}}$ & 工 $\frac{\vec{\partial}}{2}$ & 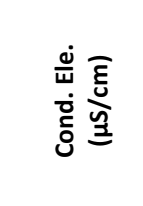 & 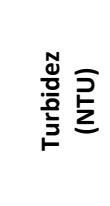 & 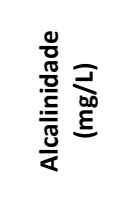 & 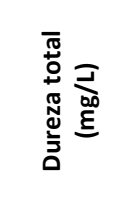 & 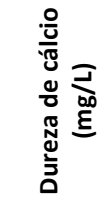 & 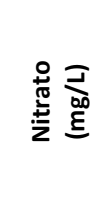 & 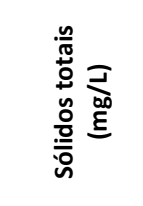 & 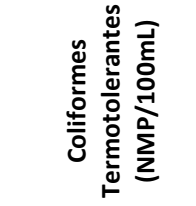 \\
\hline \multirow[t]{2}{*}{ P1 } & 5,8 & 30 & 7,6 & 2743 & 12,4 & 426 & 687 & 261 & 1,2 & 1808 & $6,4 * 10^{5}$ \\
\hline & $2,1-10$ & $28,8-31,7$ & $7,2-8,1$ & $2510-3020$ & $6,3-18,4$ & $80-600$ & $620-732$ & $180-308$ & $0,2-4,0$ & $1575-2072$ & $1,3 * 10^{5}-3,5 * 10^{6}$ \\
\hline \multirow[t]{2}{*}{ P2 } & 3,7 & 29 & 7,4 & 2737 & 13,6 & 367 & 732 & 283 & 2,4 & 2010 & $7,4 * 10^{4}$ \\
\hline & $1,4-6,2$ & $27-31,6$ & $6,9-8,0$ & $2460-2940$ & $2,1-32,4$ & $80-480$ & $640-808$ & $172-406$ & $0,2-9,5$ & $1677-2328$ & $1,3 * 10^{3}-2,3 * 10^{5}$ \\
\hline \multirow[t]{2}{*}{ P3 } & 5,8 & 28 & 7,3 & 647 & 9,9 & 110 & 158 & 71 & 2,3 & 440 & 220 \\
\hline & $3,8-8,0$ & $26,6-29,9$ & $6,1-8,1$ & $418-897$ & $3,9-31,3$ & $30-166$ & $116-206$ & $60-82$ & $0,5-7,3$ & $192-733$ & $170-9 * 10^{3}$ \\
\hline \multirow[t]{2}{*}{ P4 } & 7,9 & 29 & 7,7 & 630 & 9,7 & 98 & 164 & 84 & 1,2 & 466 & $2,8 * 10^{3}$ \\
\hline & $6,2-9,6$ & $27,1-31,7$ & $7,2-8,3$ & $393-880$ & $3,4-24$ & $100-130$ & $120-222$ & $64-122$ & $0,1-2,7$ & $308-765$ & $200-1,6^{*} 10^{4}$ \\
\hline \multirow[t]{2}{*}{ P5 } & 8,1 & 28 & 7,7 & 645 & 9,6 & 99 & 171 & 81 & 1,4 & 481 & 485 \\
\hline & $5,4-10,5$ & $27,5-28,8$ & $7,3-8,7$ & $408-887$ & $3,5-35,6$ & $28-130$ & $140-232$ & $62-126$ & $0,6-2,1$ & $346-785$ & $20-6,8^{*} 10^{4}$ \\
\hline VMP & $\geq 5^{(1)}$ & --- & 6 a $9^{(1)}$ & $100^{(4)}$ & $100^{(1)}$ & $400^{(3)}$ & $500^{(3)}$ & --- & $10^{(1)}$ & --- & $<1000^{(2)}$ \\
\hline
\end{tabular}

(1)-Resolução CONAMA 357/05; (2)-Resolução CONAMA 274/00; (3)-Portaria de Consolidação no 5/2017, Ministério da Saúde; (4)-Estudos de Marcos Von Sperling (2014).

Dos trechos monitorados, os que mais apresentaram resultados insatisfatórios foram P1 e P2, possuindo valores acima do padrão recomendado em praticamente todos os parâmetros analisados. Nesses pontos foi observada a presença constante de animais, além da interferência antrópica e de lançamento de efluentes in natura, em especial no segundo ponto - fator condicionante para compreensão da diminuição no valor de oxigênio dissolvido nesse local de coleta (Figura 3). 


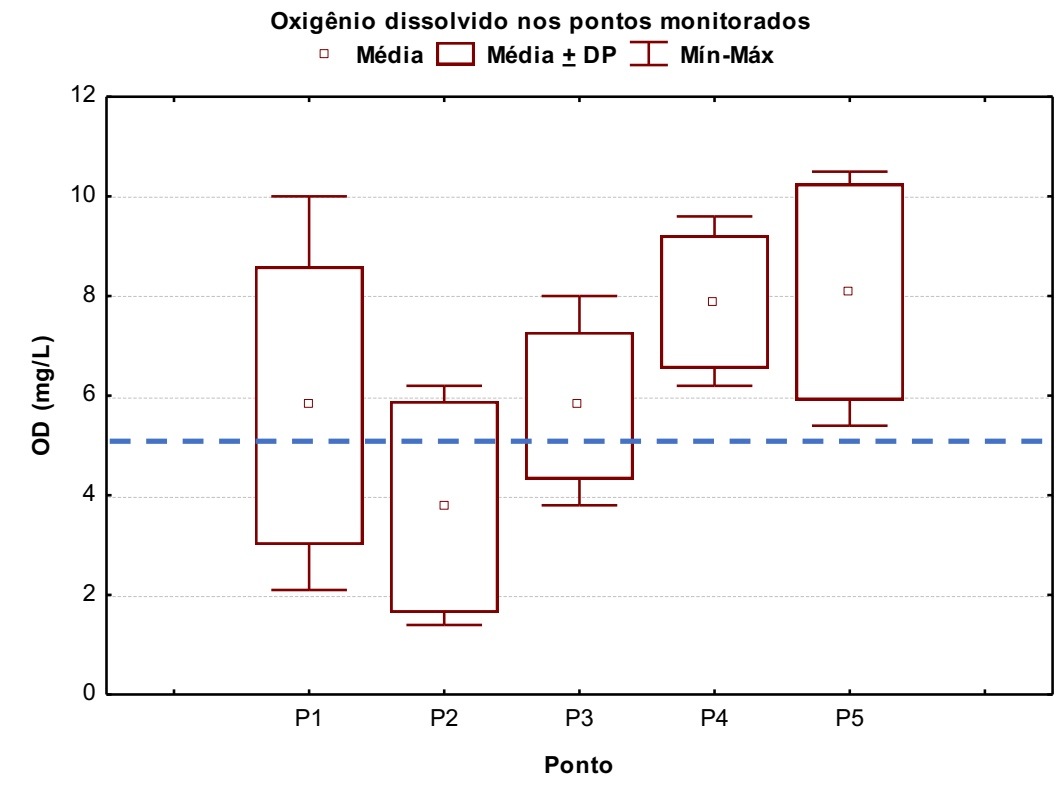

Figura 3: Concentrações de oxigênio dissolvido nos pontos monitorados.

Além do aspecto visual desagradável, pode haver um declínio dos níveis de oxigênio dissolvido, provocando riscos à sobrevivência dos seres de vida aquática, exalação de maus odores e possibilidade de contaminação de animais e seres humanos pelo consumo ou contato com essa água, dentre outros aspectos (SARDINHA et al 2008).

A redução nos valores de OD está comumente associada à poluição do manancial por efluente doméstico, fazendo com que a demanda bioquímica de oxigênio (DBO) desse corpo hídrico aumente, na medida em que o oxigênio dissolvido decline. Geralmente, isso acontece, sobretudo, nos pontos de mistura, onde o volume de matéria orgânica é maior e os microrganismos realizam a degradação dessa matéria. Teores baixos de OD podem indicar que houve uma intensa atividade bacteriana, decompondo a matéria orgânica lançada na água (MOTA, 2012).

Outro parâmetro que merece atenção é o de condutividade elétrica, indicador que não se encontra nas resoluções do CONAMA citadas nesse trabalho, mas que apresenta resultados importantes na determinação da qualidade da água de um corpo hídrico. No tocante a esse parâmetro, observa-se um aumento significativo nos dois primeiros pontos de análise, ultrapassando $2000 \mu \mathrm{S} / \mathrm{cm}$, possivelmente em decorrência dos despejos irregulares de esgoto doméstico (Figura 4).

Além desses dados, os valores de sólidos totais também se encontram alterados nestes mesmos pontos de coleta, ultrapassando a concentração de 1000 mg/L de sólidos totais (Figura 5). Os valores de condutividade se relacionam com os valores de sólidos totais dissolvidos, 
levando a crer que a crescente nesses dois parâmetros se dá em decorrência da característica do tipo de poluente que chega ao manancial e que essas substâncias estão, em sua maioria, na forma dissolvida.

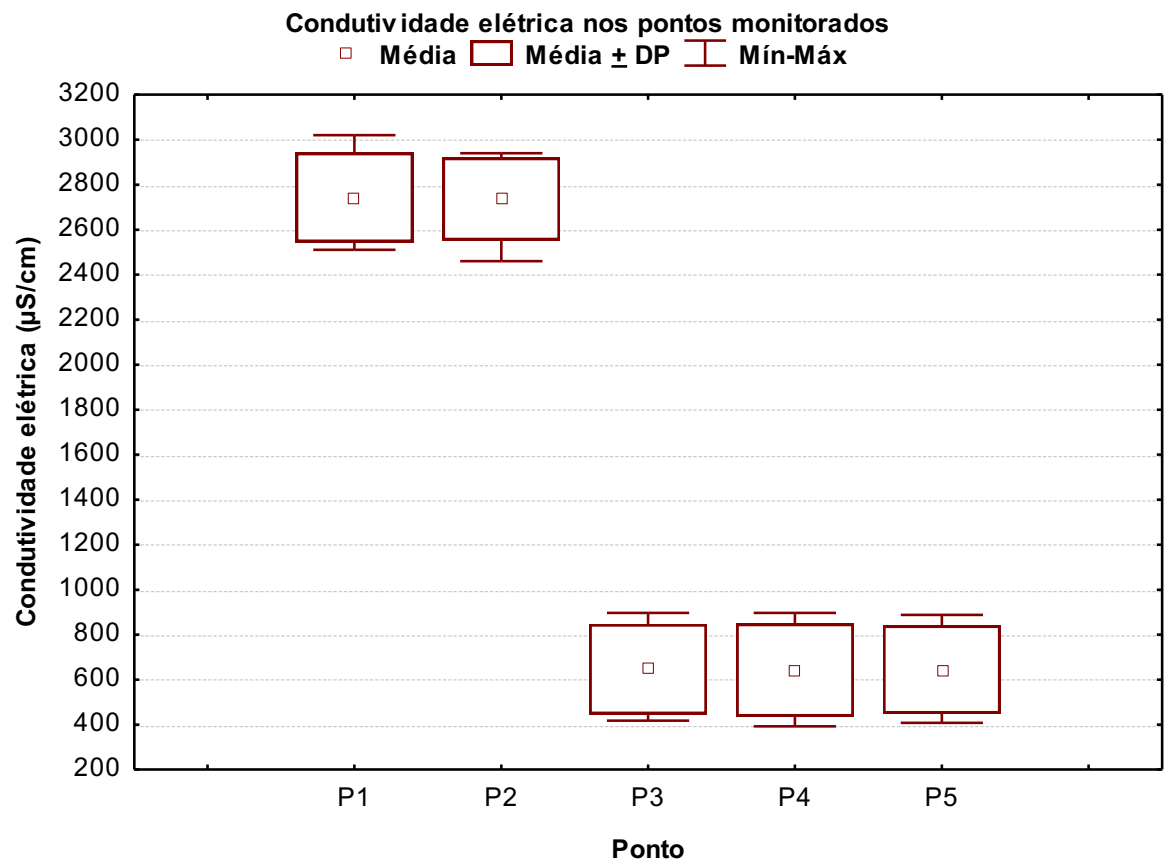

Figura 4: Concentrações de Condutividade Elétrica nos pontos monitorados.

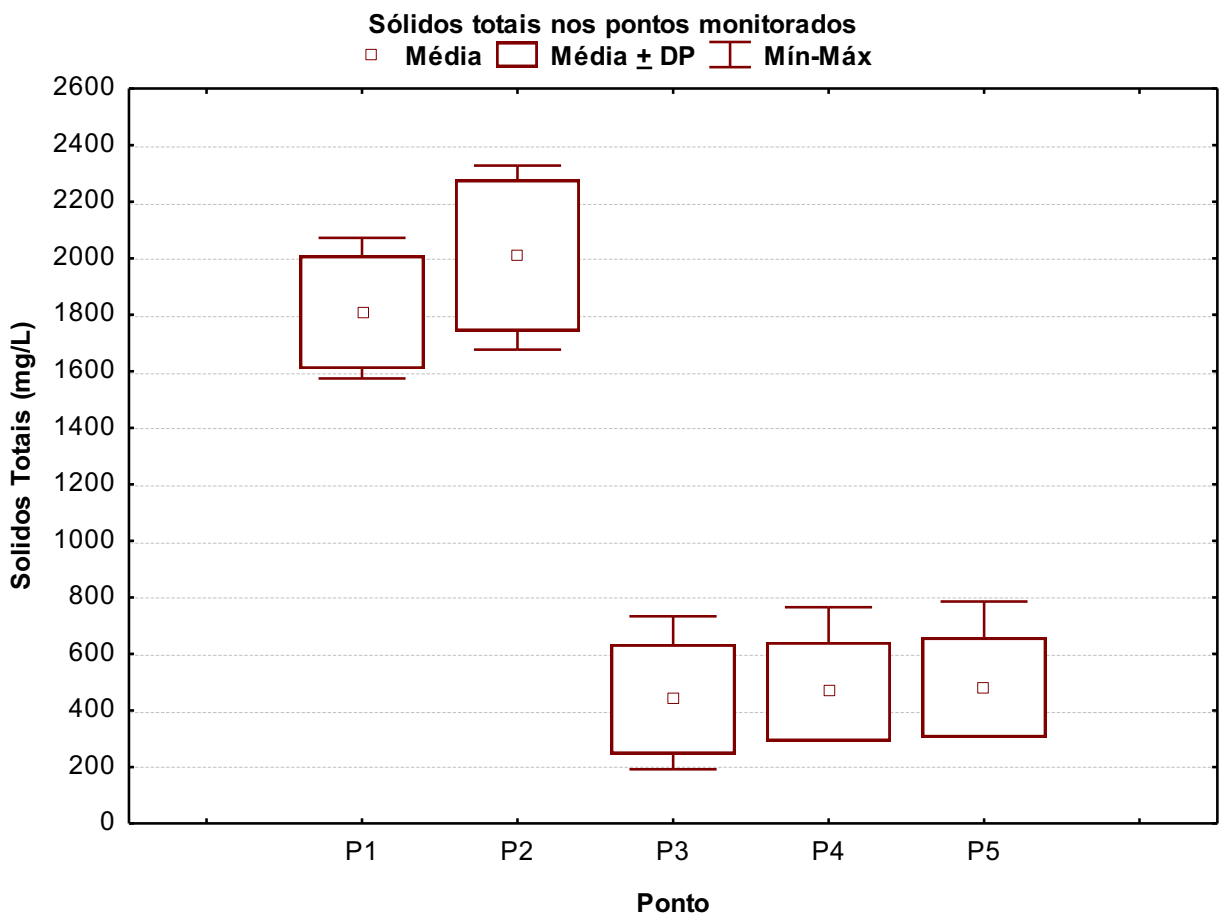

Figura 5: Concentrações de sólidos totais nos pontos monitorados. 
As águas naturais apresentam teores de condutividade elétrica na faixa de 10 a 100 $\mu \mathrm{S} / \mathrm{cm}$. Em ambientes poluídos por esgotos domésticos ou industriais os valores podem chegar até $1000 \mu \mathrm{S} / \mathrm{cm}$ (PIRATOBA et al 2017). Percebe-se na Figura 4 que os valores de P1 e P2 encontram-se bem acima do que é considerado padrão nos estudos de Von Sperling (2014).

Ainda relacionado aos dois primeiros pontos de coleta, quando analisados os valores para alcalinidade, dureza de cálcio e dureza total, observou-se um acréscimo indicativo de despejo inadequado de efluente doméstico, e, consequentemente, de degradação do manancial, causando prejuízo ao seu uso e a toda comunidade aquática. Esses parâmetros estão relacionados com a presença de detergentes, sabões, óleos e graxas, que, possivelmente, chegam até o rio através de ligações clandestinas de esgotos.

Um dos parâmetros que não obteve alterações, mas é digno de atenção, é o valor de nitrato das amostras. O nitrato é um importante indicativo de poluição por esgoto doméstico, sendo possível indicar se aquela poluição é antiga ou recente, estando ainda relacionado com a ocorrência de algumas doenças, principalmente a metemoglobinemia. Nas amostras em estudo, as concentrações se apresentaram baixas, não chegando a $3 \mathrm{mg} / \mathrm{l}$ de $\mathrm{NO}_{3}$, conforme se observa na Figura 6.

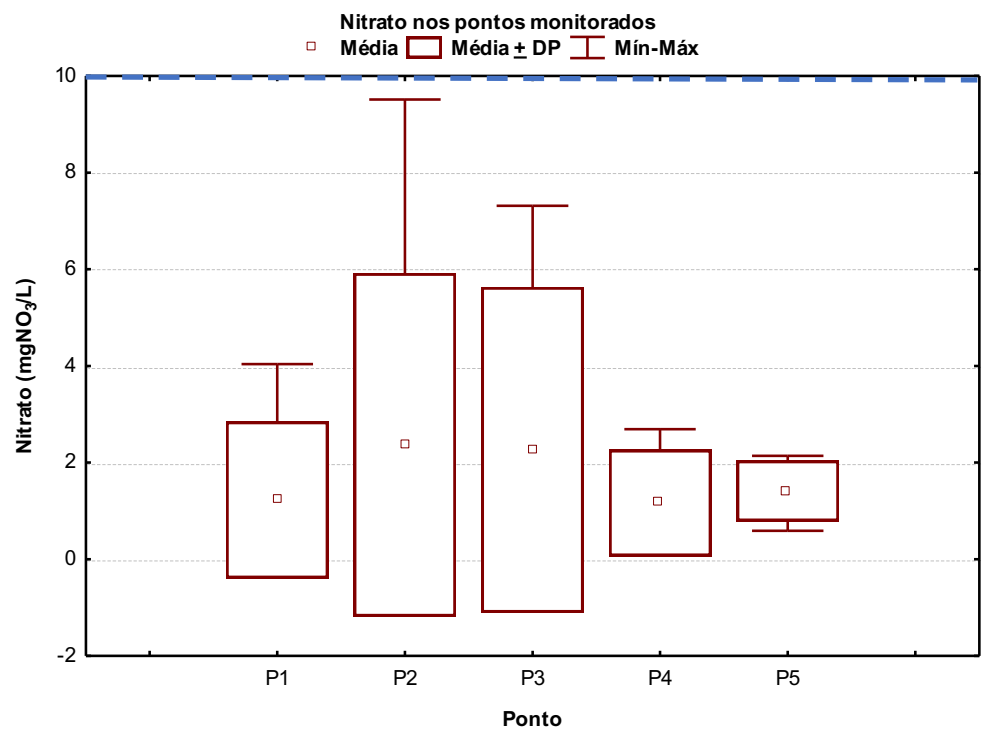

Figura 6: Concentrações de nitrato nos pontos monitorados.

Esses nutrientes enriquecem o meio aquático, favorecendo o crescimento de plantas aquáticas, como as macrófitas aquáticas e algas. O grande problema é a predisposição ao surgimento de cianobactérias potencialmente tóxicas, as quais podem alterar a qualidade das águas, sobretudo as utilizadas no abastecimento público, possibilitando graves riscos à saúde. (COSTA et al., 2016). 
Como os valores de nitrato estão abaixo do esperado, compreende-se que a porção de nitrogênio presente na água está na forma de nitrogênio amoniacal. Altas concentrações de amônia podem causar sufocamento em peixes. Ela é formada pela decomposição da matéria orgânica (uréia e amônia), e, normalmente, está em concentração elevada em locais poluídos (RUZISKA, 2008).

Dois outros parâmetros também não definidos nas resoluções do CONAMA, anteriormente citadas, são dureza e alcalinidade. Elevadas concentrações de dureza e alcalinidade estão geralmente associadas à presença de detergentes, sabões, óleos e graxas na água (Figura 7). Tendo em vista a importância desses parâmetros para determinação da qualidade da água e comprovação da possível contaminação de origem sanitária, as concentrações foram comparadas com os padrões da Portaria de Consolidação no 05/2017 do Ministério da Saúde.

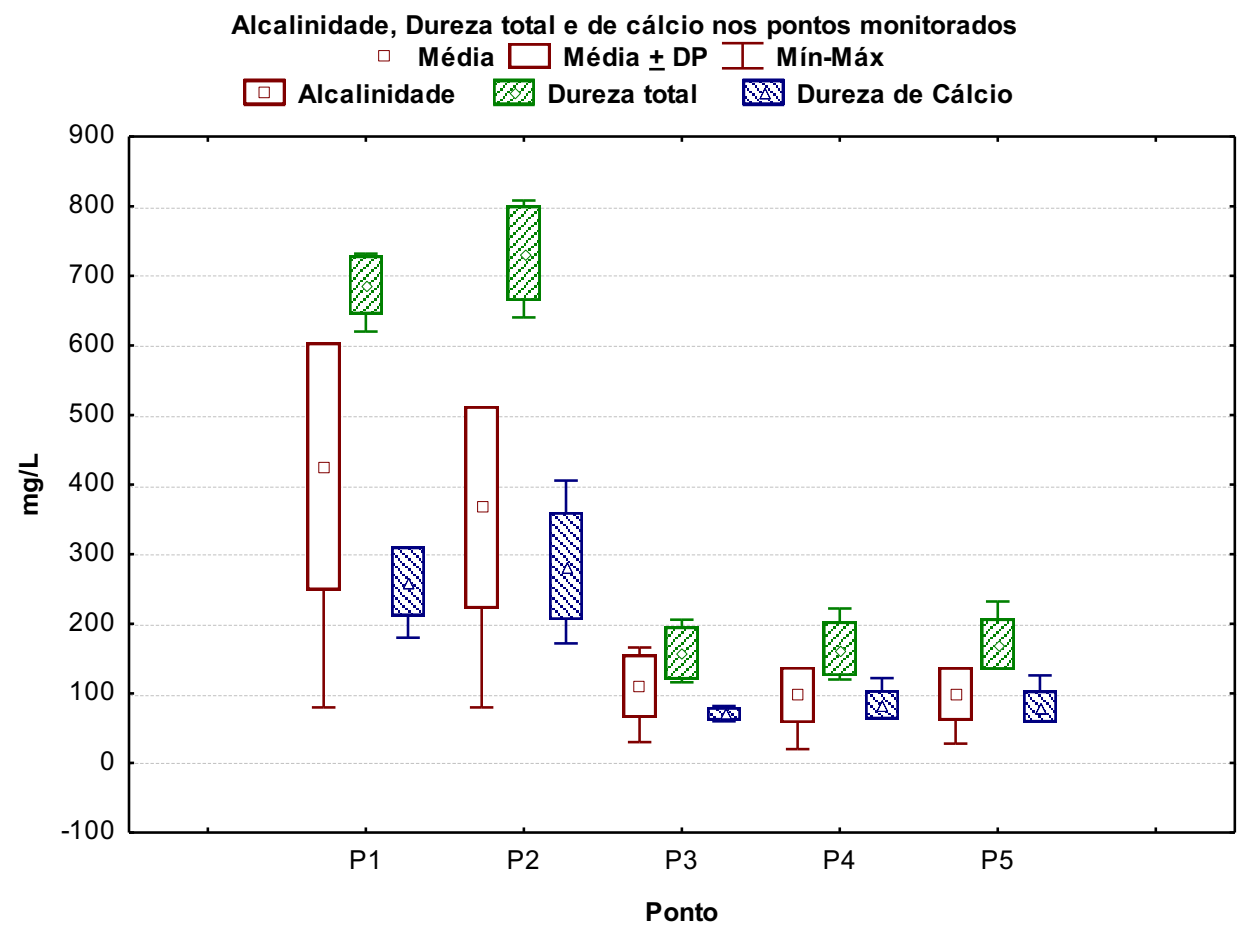

Figura 7: Relação entre dureza total, dureza de cálcio e alcalinidade nos pontos monitorados

Ao final, têm-se ainda os resultados das análises para coliformes termotolerantes, que evidenciam ainda mais a situação preocupante do Rio Potengi na localidade de São Paulo do Potengi. As bactérias do grupo coliforme termotolerantes são utilizadas como indicadores de contaminação fecal, ou seja, indicam se a água foi contaminada por fezes e, consequentemente, se apresenta potencialidade para transmitir doenças. (VON SPERLING, 2014). 
Todos os pontos monitorados apresentaram coliformes termotolerantes.Em alguns casos, no entanto, conforme apresentado na Figura 8 , os valores chegaram a aproximadamente $10^{6}$ NMP/100 mL, ultrapassando o referencial permitido pela Resolução CONAMA 274/00, que define os critérios de balneabilidade em águas brasileiras.

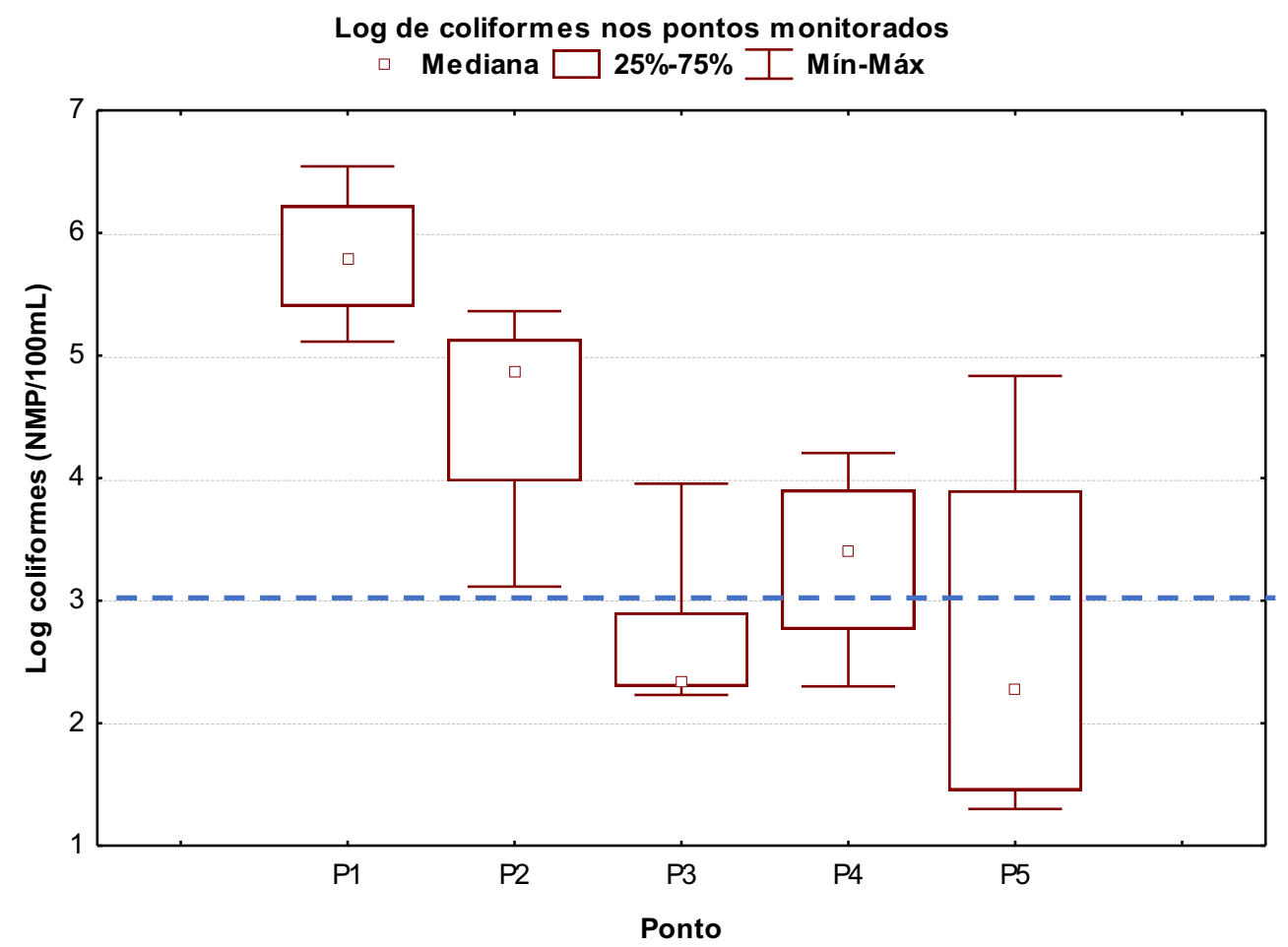

Figura 8: Concentrações de coliformes termotolerantes nos pontos monitorados.

A presença desse grupo de bactérias na água tende a indicar focos de contaminação fecal no local ou em suas adjacências, além de sinalizar a possível presença de microrganismos patogênicos causadores de diversas doenças de veiculação hídrica e de origem sanitária.

Os resultados obtidos mostram que diversos parâmetros estão em desconformidade com os valores estabelecidos pelas resoluções vigentes no país, que delimita o enquadramento de águas superficiais e os usos dessas águas. A alteração na qualidade da água é oriunda, principalmente, do despejo irregular dos efluentes provenientes da cidade de São Paulo do Potengi. Apesar de contar com uma rede coletora de esgoto, esta não atende a toda cidade e não funciona como deveria, já que os efluentes coletados não chegam à ETE (Estação de Tratamento de Efluentes), sendo desviados pelas estações elevatórias para o Rio Potengi.

Diversos trechos do rio recebem contribuições de efluente doméstico de forma direta ou indireta, como se pode observar nas Figuras 9 e 10, que apresentam o despejo irregular de maneira evidente. Desde o momento de seu lançamento, esse despejo irregular altera as 
características que conferem a qualidade da água, tornando as adjacências do rio um lugar insalubre e com diversos focos causadores de doenças.

Além disso, em alguns desses pontos, é possível observar também o despejo irregular de resíduos sólidos urbanos e a criação de alguns animais como cavalos e bois em seus entornos, além da ausência da mata ciliar e assoreamento em alguns trechos do rio. Tais fatores prejudicam ainda mais a situação sanitária e ambiental do recurso hídrico em questão.

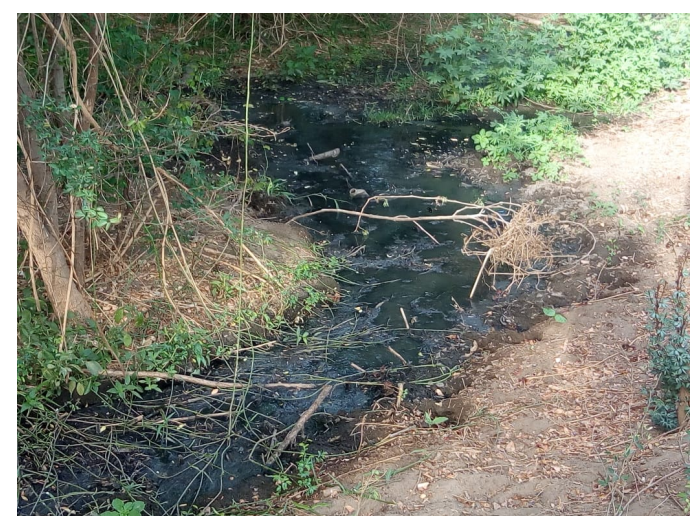

Figura 9: Despejo irregular de efluentes domésticos nas proximidades do P1.

Fonte: Acervo dos autores

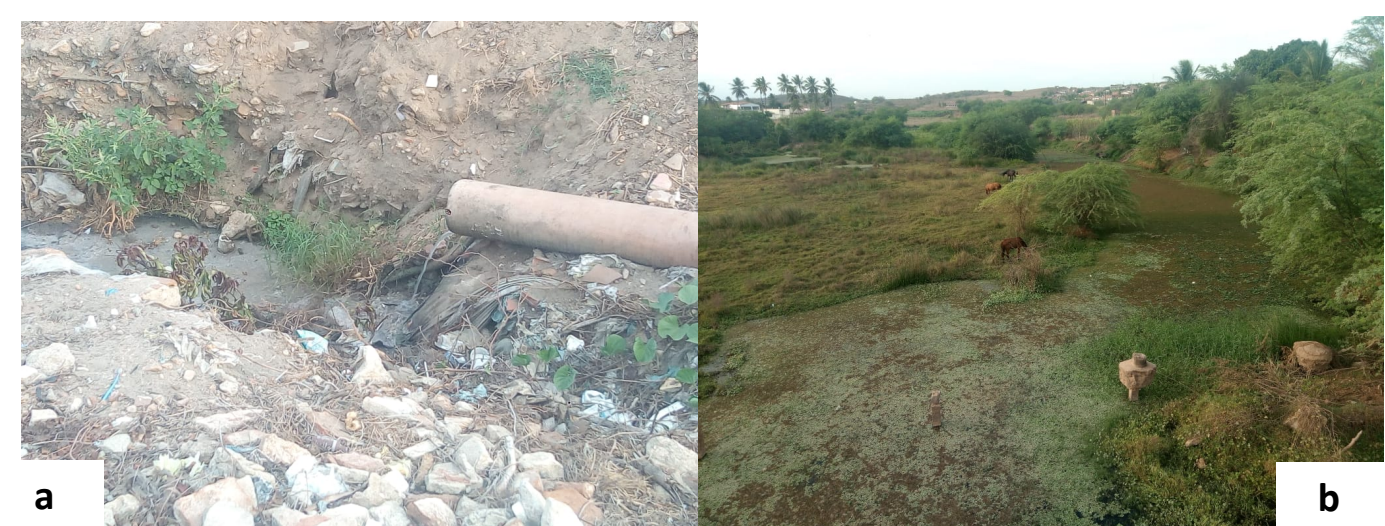

Figura 10: Disposição inadequada de resíduos sólidos e efluentes domésticos (a) e animais sendo criados nas adjacências (b).

Fonte: Acervo dos autores

\section{CONCLUSÕES}

Levando-se em consideração os aspectos observados, percebe-se a importância da pesquisa, em especial na cidade de São Paulo do Potengi, visto que os moradores ainda fazem uso das águas do Rio Potengi para algumas atividades domésticas, agrícolas e comerciais. 0 conhecimento sobre o grau de poluição e sobre os prejuízos decorrentes do uso dessa água é essencial, podendo assim ser utilizado como um instrumento de conscientização da comunidade e dos gestores municipais. 
São notórias as alterações que aconteceram no rio. A sua qualidade ambiental e sua capacidade de suporte foram afetadas, prejudicando seus mais diversos usos, sobretudo atividades de lazer e de pesca, que ainda são muito realizadas, mesmo que em desacordo com os diversos parâmetros estabelecidos pelas resoluções vigentes no país, destacando-se entre elas a CONAMA $n=274 / 00$.

A pesquisa possibilitou ainda conhecer o nível de poluição do manancial e suas fontes causadoras. A origem do problema, destacada no trabalho, está relacionada à precariedade do sistema de esgotamento sanitário da cidade, que motiva a condução sem tratamento de parte dos efluentes, nela produzidos, para o rio Potengi.

\section{REFERÊNCIAS BIBLIOGRÁFICAS}

APHA, AWWA, WEF. Standard Methods for theExaminationofWaterand Wastewater.23 ed. New York: AmerincanPublic HealthAssociation Inc., 2017.

BRASIL. Ministério da Saúde. Fundação Nacional da Saúde. Caderno de Pesquisa em Engenharia de Saúde Publica. Brasília: Funasa, 2013. 256 p.

CONSELHO NACIONAL DO MEIO AMBIENTE (CONAMA). Resolução no 357, de 17 de março de 2005. Brasília, 2005. Disponível em: http://www2.mma.gov.br/port/conama/res/res05/res35705.pdf>. Acesso em: 22 de ago. de 2018.

CONSELHO NACIONAL DE MEIO AMBIENTE (CONAMA). Resolução 274, de 29 de novembro de 2000. Brasília, 2000. Disponível em: http://www2.mma.gov.br/port/conama/legiabre.cfm?codlegi=272>. Acesso em: 22 de ago. de 2018.

COSTA, Juliana da Silva et al (2016). Avaliação da Eutrofização no Rio Potengi, situado no município de São Paulo do Potengi/RN por meio das metodologias de Branco (2004) e teorema de Bayes. Disponível em: https://editorarealize.com.br/revistas/conidis/trabalhos/TRABALHO_EV064_MD1_SA5_ID896_2 4102016214705.pdf> Acesso em: 23 de ago. de 2018.

FIGUEIREDO, F. F.; FERREIRA, J. G. O Saneamento Básico no Nordeste e no Rio Grande no Norte: avanços constrangimentos. Disponível em: < http://anpur.org.br/xviienanpur/principal/publicacoes/XVII.ENANPUR_Anais/ST_Sessoes_Temati cas/ST\%204/ST\%204.7/ST\%204.7-04.pdf>. Acesso em: 22 de ago. de 2018.

IBGE - INSTITUTO BRASILEIRO DE GEOGRAFIA E ESTATÍSTICA. Disponível em: < https://www.ibge.gov.br/>. Acessado em 10nov 2019.

MELLO, F. A.; OLIVO, A. M. Recursos hídricos: poluição, escassez, qualidade microbiológica e química da água. Disponível em: 
<http://www.unoeste.br/site/enepe/2016/suplementos/area/Vitae/Biomedicina/RECURSOS\%20 H\%C3\%8DDRICOS\%20POLUI\%C3\%87\%C3\%830,\%20ESCASSEZ,\%20QUALIDADE\%20MICROBIOL\%C 3\%93GICA\%20.._.pdf>. Acesso em: 23 de outubro de 2018.

MOTA, Suetônio. Introdução à engenharia ambiental. Rio de Janeiro: ABES, 2012.

Ministério da Saúde. Portaria De Consolidação № 5, de 28 de setembro de 2017. Brasília, 2017. Disponível em:

http://bvsms.saude.gov.br/bvs/saudelegis/gm/2017/prc0005_03_10_2017.html>. Acesso em: 22 de ago. de 2018.

PIRATOBA, A. A. et al (2017). Caracterização da qualidade da água na área portuária de Barcarena, PA, Brasil. Rev. Ambient. Água, Taubaté, Vol. 12 n.3, may/jun, 2017.

PLANO MUNICIPAL DE SANEAMENTO BÁSICO DO MUNICÍPIO DE SÃO PAULO DO POTENGI. São Paulo do Potengi, 2011.

RUZISKA, A. A. (2008). Impactos ambientais sobre os recursos hídricos para abastecimento público em São Jose dos Campos (SP). Dissertação (Dissertação em AnaliseGeoambiental) - UNG, Guarulhos, p.70. 2008.

SARDINHA, D. S. et al (2008). Avaliação da qualidade da água e autodepuração do ribeirão do meio, Leme (SP). Eng. Sanit. Ambient. vol.13 no.3 Rio de Janeiro July/Sept. 2008.

SMITH, V. H. \& SCHINDLER, D. W. Eutrophicationscience: where do we go fromhere? Trends in Ecologyand Evolution 24: 201-207. 2009.

VON SPERLING, Marcos. Introdução à qualidade das águas e ao tratamento de esgotos. 40 Edição. Belo Horizonte: Editora UFMG, 2014.

SILVA, E. F. L. P. et al (2011). Avaliação da qualidade da água em microbacias hidrográficas de uma Unidade de Conservação do Nordeste do estado de São Paulo, Brasil. R. bras. Bioci. Porto Alegre, v. 9, n. 3, p. 371-381, jul./set. 2011. 